\title{
Tempo, idade e cultura: uma contribuição à psicopatologia da depressão no idoso. Parte II: \\ Uma investigação sobre a temporalidade e a medicina
}

\author{
Cláudio Lyra Bastos
}

Procuramos aqui relacionar dois aspectos fundamentais das intuições culturais sobre a passagem do tempo - a temporalidade cíclica e a contínua com a terapêutica médica e especialmente com a psicopatologia, numa visão crítica do constructo moderno da depressão no idoso. Inspirado em perspectivas de natureza antropológica, o texto se apóia na experiência clínica cotidiana e na atitude fenomenológica que orienta essa prática. Nas concepções culturais que tendem a perceber a passagem do tempo de forma predominantemente cíclica, o envelhecer é parte de um movimento eterno, e a família se perpetua em seus descendentes, nas suas tradições, no vínculo com a terra ou no exercício do ofício familiar. As transformações culturais que têm proporcionado a passagem para enfoques mais direcionais do tempo vão destacando cada vez mais o papel individual na história social. Quanto mais difícil for a passagem de Weltanschauungen tradicionais - de tendência circular, fatalista, repetitiva e eterna - para outras de tendência individualizante, burocratizante, planejadora e sucessiva, maiores as dificuldades para uma senectude satisfatória e maior a tendência à medicalização desse fracasso. Esta é a primeira (segunda) parte de uma série de três artigos.

Palavras-chave: Psicopatologia e cultura, temporalidade e medicina, depressão no idoso, psicogeriatria 


R E V V I S S T A
LATIN OA M ERICA N A
DE PSICO PATO LOG G IA
F U N D D A M E N T A L
ano IX, N. 1, mar/2006

\section{As vivências do tempo como ciclo e como continuidade}

Como vimos anteriormente (Bastos, 2005), duas concepções filosóficas e culturais básicas sobre a natureza do tempo persistem desde a antigüidade até os nossos dias: a noção de tempo cíclico, rotativo ("roda" do tempo) e a de tempo contínuo, seqüencial, histórico, progressivo ("flecha” do tempo). No dizer de Leach (1977):

Estou inclinado a pensar que todos os outros aspectos do tempo, duração ou seqüência histórica, por exemplo, são apenas simples variações destas duas experiências básicas: a) que certos fenômenos se repetem; b) que as mudanças da vida são irreversíveis. Agora, a nossa visão moderna e sofisticada tende a jogar a ênfase no segundo destes aspectos do tempo.

Na primeira, o tempo é visto como uma roda, ou uma série de rodas menores que giram em círculos maiores, onde os eventos periodicamente se repetem. $\mathrm{Na}$ segunda, o tempo é visto como um fluxo contínuo, sob uma perspectiva histórica, onde os eventos jamais se repetem, e o passado forma o presente e ambos conduzem ao futuro. A afirmação do filósofo grego Heráclito expressa bem esta idéia: "Ninguém se banha duas vezes no mesmo rio", pois nem mais a pessoa nem o rio serão os mesmos.

O hinduísmo, o budismo mahayana, os cultos chineses aos ancestrais tendem a concepções de círculos maiores ou menores de tempo, com retornos periódicos. Já o budismo hinayana, assim como as concepções monoteístas judaico-cristã e islâmica admitem um tempo de fluxo contínuo com um clímax no final dos tempos, ou Apocalipse, e no julgamento, ou Juízo Final (Eliade, 1949, 1993; Needham, 1971; Toynbee, 1994).

A idéia de evolução ou avanço no tempo está profundamente entranhada na vida moderna, e o progresso é tido como um valor em si mesmo. As relações entre os povos e culturas se estabelecem em termos evolutivos (Fabian, 1983). “Atraso" significa algo intrinsecamente ruim, assim como "avanço”, algo essencialmente bom. Ninguém quer ficar "parado no tempo" ou "perder o bonde da História”. Aqui no Brasil, apesar de nos reconhecermos como "atrasados”, temos o lema "Ordem e Progresso" inscrito na Bandeira, e queremos desesperadamente "ir para a frente” e ser o "país do futuro”. Enquanto grande parte da população tende a viver os eventos de forma fatalista e naturalizante, os chamados "formadores de opinião" se digladiam quanto ao passado e o futuro; uns denegrindo este para glorificar aquele, enquanto outros fazem o oposto. 


\section{Concepções cíclicas do tempo - os deuses das doenças (Omolu)}

A idéia do tempo cíclico certamente originou-se da observação dos ciclos da natureza: dia e noite, estações do ano, plantio e colheita, ciclos de reprodução, movimentos dos astros etc. Como disse Campbell (1974), "It is a common feature of many pastoral with simple material cultures that they are highly dependent on their physical environment..." Como mencionamos anteriormente, ocorre aqui uma tendência a temporalizar as relações espaciais, submetendo-as ao jugo do Tempo soberano.

As sociedades iletradas, predominantemente extrativistas, nômades, seminômades (transumantes) e agrícolas tendem a ter como principal referência um conceito de tempo concebido como repetitivo e circular. Seu ritmo de mudanças é extremamente lento, quase a-histórico. Whitrow (1993) menciona o clássico exemplo dos índios Hopi, do Arizona, que não se referem ao passado nem ao futuro. Relata que B. L. Whorf, tendo estudado minuciosamente a sua língua, não conseguiu encontrar quaisquer "palavras, formas gramaticais, construções ou expressões referentes ao tempo ou a qualquer de seus aspectos."

Evans-Pritchard (1978) assinalou que para os Azande, do sudoeste do Sudão, o presente e futuro se superpunham. Em seu livro clássico The Nuer, ele observa que o tempo, para os Nuer, apresenta dois aspectos: 1. claramente cíclico, ligado aos ciclos da natureza que se repetem, que ele chamou de tempo ecológico. As estações do ano, as secas, as chuvas, as pastagens e as colheitas determinam a passagem do tempo. Observa que os Nuer pouco usam os nomes dos meses para indicar épocas, mas preferem referir-se a alguma atividade que esteja em curso naquele momento. Em nosso meio rural, podemos constatar o mesmo hábito, com as pessoas reportando-se às águas, à seca, ao milho, ao ponto do feijão, ao estado do pasto, às capineiras, à silagem etc. como referências temporais; 2. o tempo que se refere às relações internas da estrutura social. O tempo estrutural parece ser progressivo, mas na realidade trata-se de uma ilusão, pois a estrutura permanece a mesma e o tempo é percebido como o movimento de pessoas ou grupos, por meio da estrutura.

Os antigos egípcios, cuja vida dependia das periódicas cheias do Nilo, apesar de todas as conquistas de sua civilização, mantiveram-se numa perspectiva predominantemente não-contínua. Os aspectos estereotipados, com figurações repetitivas, em que a representação formal e hierárquica predomina sobre a particularidade e o movimento são característicos na arte egípcia.

A religião judaica em geral tende a uma visão contínua do passar do tempo, e as primeiras marcações do tempo, independentes dos ciclos naturais, surgiram entre os judeus (ver Zerubavel, 1985). Apesar disto, encontramos também alguns 


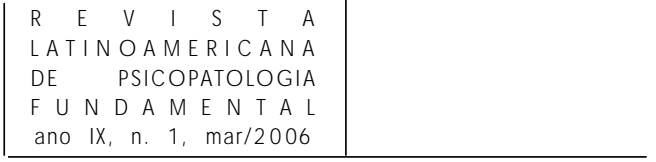

aspectos fatalistas e cíclicos no Antigo Testamento (ver Eclesiastes, 1, 3-4 e 9-11).

Na Idade Média, apesar do cristianismo, as concepções cíclicas dos antigos celtas e outros povos, assim como muitos de seus antigos rituais, foram preservados, mesmo com a reprovação eclesiástica. Idéias fatalistas, com imagens como a da Roda da Fortuna aparecem nas cartas do tarô e na poesia profana dos Carmina Burana: "Fortuna rota volvitur, / Descendo minoratus; / Alter in altum tollitur; / Nimis exaltatus /Rex cedet in vertice / Caveat ruinam! / Nam sub axe legimus / Hecubam reginam.”

\section{Rituais de cura e sacrifícios periódicos}

Os sacrifícios astecas, os deuses que morriam anualmente (o egípcio Osíris, o babilônio Tammur, o grego Adônis, o nórdico Balder etc.), os festivais do fim do ano agrícola, representam o mesmo ciclo da vida e da morte. Mesmo no cristianismo, encontramos o sacrifício periódico, repetido, em que a morte origina a vida: a eucaristia, onde o corpo e o sangue de Cristo são ingeridos. "Em verdade, em verdade, vos digo: se o grão não cair na terra e morrer, ficará só; quando morre, porém, gera muitos frutos” (João, 12:24).

Mesmo constatando que o processo de substituição da idéia do tempo cíclico pela do tempo contínuo já poderia ser traçado desde o início da escrita e da história, vemos que essa substituição jamais se completa. A propósito deste fato, Mircea Eliade assinala que as religiões sempre celebram a restauração periódica, o eterno retorno, que purifica, recupera e lava os pecados. Em Le Mythe de l'Éternel Retour (1949), Eliade mostra que - apesar de marcarem uma concepção histórica dos mitos, com a criação, a revelação e a previsão de um final dos tempos - há “uma obsessão pela regeneração” nas doutrinas da seta do tempo, que a transformam novamente no ciclo do tempo. Encontramos algo semelhante na história da ciência (Gould, 1991 e 1999).

Assim, vemos que as concepções cíclicas do tempo tendem a predominar nas sociedades relacionais, mais hierarquizadas e conservadoras. Constatamos aí uma relativa ausência de concepções progressivas, lineares, de agendas, de programas, de história.

A doença tende, nestes casos, a ser vista como um castigo causado pelo esquecimento dos rituais e sacrifícios devidos aos deuses: gregos, hebreus, yorubas. Temos então entidades sobrenaturais encarregadas das funções patológicas, os deuses das doenças, como o orixá da varíola, chamado Omolu, ou Obaluaiê, a deusa asteca Tlazoteotl, o deus védico do fogo e da febre Agni, a 
deusa Sitala da varíola e os deuses da malária. O destino é controlado por forças externas, e só elas podem causar as doenças ou trazer a cura.

\section{Terapias cíclicas}

As terapias passam a ter um caráter tão cíclico ou periódico como os rituais cujo esquecimento motivou as doenças. Desta forma temos as bênçãos periódicas, as aspersões de água benta, as sessões de candomblé, umbanda, espiritismo etc. em possessões ritualizadas semanais. A repetição e o sofrimento são parte do tratamento, ou da penitência, e costumam ser muito bem aceitos. A relação entre provação e eficácia terapêutica é bastante evidente nas idéias de que os remédios amargos e as injeções mais dolorosas são melhores, ou de que deve-se fazer um tipo de "resguardo" durante o tratamento, sem bebidas nem divertimentos. Quando há uma forte relação terapêutica estabelecida, os efeitos colaterais das drogas são suportados com surpreendente facilidade, uma vez que são vistos como parte do tratamento e não como algo indesejável, à parte.

\section{Concepções contínuas do tempo - os deuses da saúde (Asclépios)}

Já os antigos gregos haviam começado a desenvolver idéias de tempo contínuo sobre as arcaicas concepções circulares. O deus Cronos (em grego Kronos, com kappa, não confundir com o substantivo comum chronos [cronos], com chi), filho do Céu e da Terra, devorava os próprios filhos; assim, não havia verdadeiramente um passar do tempo, pois ele não seria jamais sucedido por ninguém. Porém um dos seus filhos - Zeus - foi salvo por sua mãe Rhea, que o escondeu, fazendo Cronos engolir uma pedra em seu lugar. O velho Cronos (o Saturno dos romanos) era um deus agrícola, das festas cronias atenienses e das saturnais romanas, que celebravam as colheitas e propiciavam a fertilidade. A agricultura, com seus ciclos naturais e seus rituais anuais está mais ligada ao tempo cíclico; enquanto a navegação, o comércio e a indústria relacionam-se ao tempo contínuo. Com a deposição de Cronos por Zeus, enfraquece-se a tendência à temporalização do espaço e surge a espacialização do tempo, onde este é dominado e seus eventos são previstos e descritos num schedule.

Uma outra concepção mitológica da mudança na idéia do tempo é a figura de Héracles, que combateu os rituais tradicionais de sacrifício vencendo o gigante Anteu, rei da Líbia, filho de Gea, a Terra, e também Busíris, rei do Egito. Ambos sacrificavam todos os estrangeiros que lá aportavam. A vida telúrica está li- 
gada profundamente à idéia dos ciclos do tempo, do conservadorismo, da xenofobia e da busca de segurança. Aliás, por esta mesma razão, a própria idéia de agricultura é incompatível com a idéia do capitalismo moderno, como as crises comerciais internacionais não se cansam de demonstrar. Não é possível uma verdadeira equiparação entre empresas capitalistas e empresas agrícolas. Assim, no chamado Primeiro Mundo, os conflitos só se resolvem pelas soluções de compromisso, como cooperativas, empresas estritamente familiares e pesados subsídios governamentais. ${ }^{1}$ No Terceiro Mundo, o feudalismo persiste na maior parte da vida rural, e mesmo aquilo que se chama de agricultura "moderna" na realidade não passa, praticamente, da mecanização de uma exploração predatória, de baixo rendimento e altíssimos custos ecológicos e sociais. A terrível instituição do bóia-fria é um exemplo desse completo desligamento da terra que a modernização provoca. As conseqüências sociais disto estão aí à vista de todos. Uma compreensão mais profunda da questão revela que o maior problema não reside realmente na posse jurídica da terra, mas sim na perda ou na falta do vínculo afetivo e cultural com ela. O culto nacional à Deusa-Mãe, nas figuras da Virgem Maria e das diversas Nossas Senhoras, mostra esta profunda nostalgia telúrica.

Voltando à questão específica do tempo, vemos que o desenvolvimento da escrita, evidentemente, também favoreceu as tendências à continuidade e à historicidade. Certamente não foi por mero acaso que o alfabeto surgiu entre os fenícios, povo de navegadores e comerciantes. Ampliações dos intervalos de repetição são também formas de transformação dos ciclos em grandes “espirais”. A determinação do enorme intervalo entre as posições zodiacais das constelações, pela localização angular destas em relação à eclíptica, feita pelos antigos astrônomos, é um exemplo desta perspectiva. A precessão dos equinócios movimento angular do eixo da Terra - completa-se a cada 25.920 anos, o que faz com que as doze constelações zodiacais mudem de posição, após cerca de 2.160 anos. O culto dos mistérios mitraicos, de origem persa e muito difundido no mundo helênico, comemorava a substituição da constelação de Taurus por Áries, ocorrida há mais de quatro mil anos, e preparava-se para a chegada da era de Pisces. Dessa nova era esperavam grandes mudanças. Ainda hoje há quem aguarde Aquarius - que se inicia em 2200 - com essa mesma esperança. O estudioso de religiões David Ulansey (1989), em um trabalho sobre a cosmologia dos mistérios mitraicos, relata que a precessão dos equinócios foi descoberta em 125 aC., pelo astrônomo grego Hiparco. Segundo Ulansey, todo o universo estava em mudança, para os adoradores de Mitra: “... the discovery of the precession

1. A necessidade generalizada de subsídios que a produção agrícola apresenta no mundo inteiro é uma prova inconteste, objetiva e econômica desta absoluta incompatibilidade. 
would have been literally world-shaking: the stable sphere of the fixed stars was being unseated by some force apparently larger than the cosmos itself (...) The meaning of the tauroctony now becomes clear: the death of the bull aptly symbolized the end of the reign of Taurus as the constellation of the spring equinox and the beginning of the most recent era".

É talvez a partir desse alargamento dos ciclos que surgem as concepções mais contínuas do tempo, que vai passando a ser visto como uma flecha direcionada. Surgem então as idéias de um deus único, com uma meta determinada, seus profetas, um messias redentor, e a previsão de um final dos tempos antes da eternidade. Talvez a fracassada tentativa de imposição do monoteísmo por Akhenaton (ou Amenhotep III), em 1374 a.C., no Antigo Egito, já fosse um prenúncio da necessidade do estabelecimento do conceito de tempo contínuo sobre os ciclos naturais. Um deus onipotente e criador não é concebível sem a idéia de um fluxo de tempo contínuo, unidirecional. Deuses que desempenham um papel semelhante a Zeus, que rompeu com seu pai Cronos e iniciou um tempo mítico-histórico, estão presentes em diversas mitologias.

A criação de relógios mecânicos e agendas (Aveni, 1995; Landes, 1983; Matricon, 1991) marcou a mudança das sociedades que viviam no tempo natural para as que produziam o seu próprio tempo artificial. O desenvolvimento das artes plásticas e da música refletiu claramente essas novas concepções do tempo e também do espaço (Szamosi, 1994, Wertheim, 1999).

Concepções mais racionais surgiram e se sobrepuseram às idéias mágicas ou religiosas de doença, entre os gregos e também entre diversos outros povos da antigüidade. O homem-deus Asclépios (o Esculápio dos romanos) é uma representação dessa perspectiva, já que é a divinização da pessoa de um médico humano. Com Hipócrates, a doença passa a ser vista sob um aspecto mais internalizado - como uma disfunção que ocorre dentro do corpo - e tanto o médico quanto o paciente passam a adquirir alguma responsabilidade sobre a doença e sobre o seu tratamento.

Ainda assim, porém, a medicina permanece uma prática sagrada, e os médicos, seus sacerdotes (Simon, 1978). No século XIX, a Higiene ${ }^{2}$ começou a ser venerada e, no século XX, a farmacologia e os equipamentos eletrônicos entraram para o culto. Mesmo na mais extrema medicina tecnológica, a dicotomia sagrado-profano e puro-impuro permanecem claramente presentes, juntamente com o seu culto, só que desta vez transferidos para a adoração da ciência e da tecnologia.

2. De Higiéia, a Saúde, uma das filhas de Asclépios. Uma outra era Panacéia, a que tudo cura. Elas representam as duas grandes vertentes da medicina moderna, a curativa e a preventiva. 




No Brasil, ambas as perspectivas convivem de forma complexa. Como diz Roberto DaMatta (1990, p. 44): “... há um sistema, mas o que predomina não é todo, mas as partes.” Comparando eventos como Sete de Setembro - o dia da Pátria - e o Carnaval, DaMatta ressalta que o primeiro corresponde a “... uma temporalidade registrada, empírica, que tem um início documentado e que faz parte de um conjunto de momentos críticos da vida brasileira, os quais são vistos como encadeados. Esta temporalidade se mostra claramente "... marcada pelo sentido de progresso, evolução, e sobretudo, 'não-repetição'.” Já no segundo caso, “... o Carnaval se situa numa escala cronológica cíclica, que independe de datas fixas.” Observa-se assim uma cronologia cósmica, divina, que focaliza valores universais e transcendentes.

Robert Levine (1997), professor de psicologia social da Universidade da Califórnia, relata em seu livro A Geography of Time, de forma muito interessante e divertida, o seu choque cultural quando veio ao Brasil, para lecionar na Universidade Federal Fluminense, em Niterói. Diz ele: "Pela minha experiência de viagens anteriores, eu já previa dificuldades... Mas estas não seriam nada comparadas com os problemas que as idéias brasileiras de tempo e pontualidade iriam me causar.”

\section{O tempo e a saúde pública}

Meu tempo é hoje, não existe amanhã para mim. Wilson Batista, sambista das décadas de 1930 e 1940.

Meu tempo é hoje.

Eu não vivo no passado, o passado é que vive em mim

Paulinho da Viola.

O desenvolvimento histórico do conhecimento humano vem tendendo cada vez mais para a superação das concepções cíclicas pelas contínuas, de uma forma lenta e gradual. A idéia de uma história natural da doença vem se estabelecendo com a mesma força das agendas e planejamentos em geral. O desenvolvimento econômico, o comércio, a indústria e uma complexa rede de relações sociais e de trabalho não são compatíveis com filosofias de tempo descontínuo. Naturalmente tais idéias tendem a predominar nas sociedades mais individualizadas, menos pessoais, menos hierarquizadas. O tratamento médico é então encarado como a correção de uma falha, como o conserto de um defeito 
qualquer. As terapias costumam ser planejadas, tendo schedules que apresentam começo, meio e fim, com exames e verificações entre as etapas.

No campo da saúde pública vemos como exemplo dessa perspectiva o estabelecimento dos exames pré-natais, das tabelas de vacinação, dos programas de tratamento e prevenção de hipertensão, diabetes, câncer, tuberculose, hanseníase, doenças mentais, AIDS etc.

No Brasil, com toda a sua característica de sociedade dividida, cheia de ambigüidades, de duplicidades (DaMatta, 1990), temos com freqüência o uso indiscriminado de todas as concepções possíveis de saúde e doença, e a busca de tratamentos múltiplos. Uma concepção não contradiz necessariamente a outra, mas pode até legitimá-la, eventualmente, de forma complementar ou mesmo sincrética (Rabelo, 1993).

Vemos diariamente situações como a da terapia da tuberculose, em que a seqüência programada do tratamento muitas vezes não é cumprida, conduzindo às recidivas e à criação de resistência. De acordo com Natal et al. (1999), os estudos de abandono do tratamento indicam uma alta porcentagem de pacientes bacilíferos, e também altas taxas de resistência bacteriana à quimioterapia. Portanto, “... a resistência secundária decorre, muito mais, da não-aderência ao tratamento...”. Assim também ocorre com a lepra, as vacinações e mesmo com as psicoterapias de base analítica, que exigem o cumprimento disciplinado de um planejamento ou um calendário programado, e que por esta razão enfrentam grandes dificuldades em sua implantação nas populações carentes. Essas dissociações, que são muito comuns, poderiam ser talvez resolvidas ou minoradas por atitudes mais flexíveis, mas se vêem eternizadas através das radicalizações e das dicotomias impostas (Augras, 1983, 1995).

Recentemente veio à baila um episódio em que pastores evangélicos da famosa Igreja Universal andaram divulgando para a população que a lepra era uma doença incurável pela medicina, e que por isso os doentes deveriam jogar fora os medicamentos fornecidos pelo governo e procurar a cura apenas em Jesus, de quem eles acham ter adquirido o franchising.

Eles estavam na verdade jogando com uma idéia que já estava presente na consciência da população, a de que tratamento de verdade tem de ser imediato e miraculoso, ou então cíclico, ritualizado e repetitivo, objetivando a expiação e a penitência do pecador. Tratamentos complexos, múltiplos, conjugados ou que exijam planejamento ou acompanhamento progressivo não costumam ser bem aceitos pela população, e tendem a fracassar. As mesmas pessoas cuja grande capacidade de suportar o sofrimento - e realizar enormes esforços e sacrifícios em busca de tratamento, testemunhada diariamente pelos que trabalham na saúde pública - surpreendem a estes contrastando tal esforço com uma absoluta 


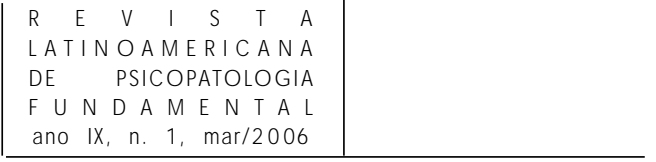

negligência quanto ao cumprimento das prescrições, dos exames ou do planejamento terapêutico. A mobilidade entre diversos enfoques e formas de tratamento é um elemento característico de nossa abordagem cultural da doença. Quando é necessária uma disciplinada aplicação a determinadas práticas terapêuticas específicas, falhamos redondamente.

Uma excelente ilustração etnográfica desse problema da estratégia terapêutica surge no livro de Anne Fadiman (1997), The Spirit Catches You and You Fall Down, que relata o caso de uma menina de etnia Hmong (imigrantes provenientes do Laos) que sofria de epilepsia (Síndrome de Lennox-Gastaut) e narra as desventuras dela e de seus pais decorrentes do absoluto desentendimento entre a família e os médicos americanos quanto à natureza da doença e os métodos de tratamento. Para os americanos, os Hmong eram criaturas primitivas e inconfiáveis, pois não respeitavam as ordens médicas, nunca cumpriam as prescrições e jamais davam os medicamentos nas doses corretas nem nas horas previstas. Para os Hmong, os médicos eram mais uma representação da prepotência, da intolerância e da opressão que o seu povo já vinha enfrentando há muitos séculos no Laos, na Tailândia e na China.

Vemos no dia-a-dia da nossa cultura uma enorme e passiva resistência ao planejamento e à previsão. Desde a pessoa encarregada do cafezinho, que só repara que é preciso comprar mais um pacote quando acaba a última colher do pó, até as mais altas instâncias governamentais, incapazes de reparar no déficit de distribuição da rede elétrica até que ocorram “apagões”. A única e clássica exceção parece ser o desfile das escolas de samba que, ao se repetir todo ano, tem o seu planejamento iniciado logo após o resultado da comissão julgadora. O tratamento médico funciona dentro dessa mesma lógica, em que as visitas periódicas ao ambulatório ou hospital não guardam qualquer correspondência com o planejamento terapêutico.

O seguinte exemplo, extraído do nosso dia-a-dia clínico, também ilustra com clareza estes fatos: uma senhora hipertensa, diabética, obesa, sofrendo de úlcera péptica, artrose e varizes, que se recusa a procurar tratamento no posto de saúde vizinho à sua casa, mostra-se capaz de pegar quatro ônibus lotados, viajando durante cinco horas, para finalmente chegar ao Hospital Universitário e dizer sorrindo ao seu médico que, infelizmente, não fez os exames pedidos, não tomou os remédios prescritos, nem se lembrou de trazer qualquer dos exames anteriormente solicitados...

Um outro exemplo típico é o caso dos exames pré-natais, freqüentemente negligenciados apesar da sua enorme importância preventiva, exaustivamente divulgada nos hospitais e postos de saúde. No entanto, vemos que não é a gravidez em si mesma que é negligenciada, mas apenas a atitude de prevenção face às suas 
possíveis complicações. Dá-se o contrário com o resguardo, período sem maior importância fisiopatológica, mas que é observado rigorosamente pela população.

O caso das vacinações infantis também é significativo: só se conseguiu vaciná-las em massa criando um “Dia da vacinação”, um evento único, meio religioso, meio carnavalesco, com bombástica divulgação pela TV. Este novo evento cultural, que passou a se repetir todos os anos, simplesmente conseguiu eliminar a poliomielite.

Nenhuma das tentativas anteriores de imposição das cadernetas e calendários programados de vacinação jamais conseguiram atingir amplamente a população. A explicação que as Secretarias e o Ministério da Saúde tinham para os fracassos era a de sempre: falta de instrução do povo. Mas nem a ignorância nem a incapacidade intelectual são explicações satisfatórias para estes insucessos, já que nenhum calendário de vacinação é mais complexo do que, por exemplo, o jogo do bicho. A origem da questão parece estar em outro lugar. Refletir profundamente sobre esses problemas, antes de se tentar tirar soluções prontas da algibeira, parece-nos fundamental.

Em seu belo livro Galinha d'angola, Vogel, Mello e Barros (1998) buscam respostas à questão: "Porque a Iaô [noviça, no rito iniciatório iorubá] deve ir à missa?”, pergunta esta que em alguns aspectos se assemelha à do médico: “Por que dona Maria insiste em vir ao Hospital Universitário, se não faz os exames nem segue o tratamento?”. Concluem eles: “Como dispositivo capaz de reduzir a complexidade real de um universo marcado pela heterogeneidade religiosa e social, o sincretismo tornou possíveis as transações significativas entre identidades fortemente diferenciadas.” Comparando o candomblé - fortemente africano - com a umbanda, de influência kardecista, diz Roger Bastide (1971): “Bem pode o espiritismo de Umbanda estar afastado do candomblé, romper com a macumba que rejeita como feitiçaria - nem por isso deixa de definir uma civilização...”

\section{Da adoração da doença à sacralização da medicina}

Os historiadores das representações sociais da doença mostram-nos que se as concepções sobre a doença claramente variam, no decorrer do tempo histórico, na sua forma e em seu conteúdo mudam muito pouco (Le Goff, 1980). O desamparo de todo ser humano face à doença e à perspectiva da morte fazem com que essas concepções, em sua essência, sejam mais ou menos as mesmas. Interpretações mágicas e religiosas das doenças - que são vistas como fatalidades ou punições - persistem até hoje. Interpretações racionais e naturalistas já existiam há centenas ou milhares de anos, entre médicos gregos como Hipócrates, assim 
Num país como o Brasil, essa interação encontra-se ainda incipiente, persistindo uma dicotomia entre uma cultura médica dita popular e uma cultura médica dita científica. Um interessante trabalho realizado em São Paulo (Queiroz, 1993), abordando as necessidades de saúde como um elemento de consumo, mostrou claramente que o cientificismo “mágico” estabelece a única passagem entre ambas, mas que, na realidade, não chega a ocorrer diretamente um contato real e significativo entre a cultura científica e a não científica. A pesquisa foi realizada numa comunidade periférica aonde foi instalado um serviço médico público moderno, de alta qualidade, com médicos da Unicamp, jovens, bem preparados para a prática de uma medicina popular estritamente científica e voltada para a saúde pública. No entanto, apesar da gratuidade e do bom nível do seu trabalho, constataram que, em diversas situações, por prescreverem pouco e pedirem poucos exames, acabavam sendo preteridos pelo público em favor dos médicos antigos da região. Quando dispunha de algum dinheiro, o povo parecia preferir a medicina "tradicional” dos médicos e farmacêuticos locais que, num falso paradoxo, mostrava-se muito mais modernosa, valorizando exames e medicamentos em profusão. A tendência de aproximação entre os extremos revela que na realidade não há grandes diferenças entre o tecnicismo e as práticas tradicionais. Já com relação à prática médica mais afeita ao rigor científico, existe um profundo abismo. Como se viu, a prática "tradicional”, usando "mal” a tecnologia moderna, acaba tendo muito mais apelo frente à população do que a prática da "boa” medicina, que a população considera pouco sensível às suas necessidades subjetivas, mostrando-se mesquinha em seus recursos aos “deuses” tecnológicos e avara na distribuição de “milagres” farmacêuticos.

Assim, constatamos que muitos problemas da saúde pública situam-se além da mera falta de verbas, e necessitam de outros recursos para a sua compreensão. Para que a medicina possa servir bem à sociedade, é necessária uma ampla compreensão das necessidades da população, vistas de uma maneira muito mais abrangente do que a utilizada pela medicina social. Como se vê, não se trata apenas de um conceito como illness contra outro conceito como disease (Kleinman, 1988), mas da permanente interação entre eles. A presença do conhecimento verdadeiramente científico na medicina só pode se dar por dentro da sua existência como cultura, ideologia e desejo, e nunca contra a influência cultural, ideológica ou psicológica em sua formação. Essa visão da ciência como uma vestal intocada já não tem mais sentido hoje em dia, o que de maneira alguma tira o seu valor, ou a iguala a qualquer feitiçaria. 


\begin{tabular}{lccccc|l}
$R \quad E$ & $V$ & $I$ & $S$ & $T$ & $A$ \\
LATIN O A M E RIC A N A & \\
$D E$ & PSICO PATO LO GIA & \\
$F$ U N D A M & E N T A L & \\
ano IX, & n. & 1, & mar/2006 & \\
\hline
\end{tabular}

\section{Níveis de autoconsciência}

Podemos distinguir, em quaisquer dos diferentes níveis ou instâncias da consciência humana, uma série de dicotomias ou de oposições dialéticas. Todas elas, porém, parecem guardar complexas relações entre si, ao constituírem a personalidade.

Podemos chamar de níveis alopsíquicos ou psicossociais aqueles que situam o sujeito no mundo. Assim, temos um nível temporal onde podemos ver a concepção do tempo como um ciclo eterno ou como uma continuidade histórica. Temos um nível espacial onde distinguimos realidade externa e interna. Observese que aqui não nos referimos à percepção do tempo nem do espaço, mas sim à relação da consciência interna com estes conceitos.

Podemos chamar de níveis autopsíquicos os que situam o sujeito em si mesmo. Teríamos assim uma consciência influenciada ou uma consciência autodeterminada. No que se refere à chamada consciência moral, encontramos as tendências à atribuição de responsabilidade externa ou interna.

Podemos chamar de níveis sociorrelacionais os que situam o sujeito na vida social e cultural. Teríamos assim uma consciência tendendo ao personalismo (hierarquizado) ou uma consciência tendendo ao individualismo (igualitário).

Podemos ainda chamar de nível existencial aquele que se refere à plenitude do sujeito em sua capacidade de apreensão da realidade (que proporcionará condições para a compreensão, a escolha e a determinação). Assim, podemos ter uma consciência massificada ou uma consciência independente e reflexiva.

\section{A internalidade e a externalidade}

Internalidade e externalidade são conceitos que se referem à atribuição de responsabilidade pelos eventos. Na psicologia, os termos antagônicos “intrapunitivo” e "extrapunitivo” foram cunhados por Saul Rosenzweig (ver Rotter, 1966) para indicar o sentido (interno ou externo) da reação individual à frustração ou à responsabilização. O psicanalista e antropólogo francês Tobie Nathan (1995) também destacou a tendência à internalidade nas culturas ocidentais modernas, por oposição às africanas, tanto no que se refere à atribuição da causa doença como ao seu tratamento, seja este medicamentoso ou psicoterápico. Logo, tanto a psicanálise como o psicofármaco tratam de um problema interno - seja físico ou psíquico - do indivíduo, ao contrário do ritual possessivo e da beberagem ou da "garrafada”, que tratam de problemas externos da pessoa, como “encosto", "mau-olhado" etc. Assim, nos estados depressivos - de esvaziamento afetivo - 
existe uma tendência à paranóia (perseguição extrapunitiva) nos deprimidos externalizantes, enquanto se observa uma predominante tendência à culpa (perseguição intrapunitiva) nos deprimidos internalizantes (Bastos, 1995). A constituição da moralidade, ou seja, da estrutura do superego, está estreitamente ligada às concepções socioculturais (ideológicas, míticas, religiosas) dos elementos que exercem o controle social sobre o sujeito numa determinada sociedade. Esta Nêmesis - o elemento punitivo (perseguidor) presente em cada membro do grupo - coloca-se de maneira diversa nas diferentes culturas (Stainbrook, 1954; Sow, 1977 e 1978; Sougey, 1992).

Nos grupos sociais com menor nível de organização - ditos “primitivos” o sujeito tende a externalizar a punição (exercida pelo grupo social) sob a forma de perseguição sobrenatural. A punição visa, sobretudo, disciplinar as relações entre o sujeito e o grupo como um todo. Este é simbolizado pela entidade sobrenatural. As sociedades modernas, urbanizadas e mais complexamente organizadas, inclinam-se para um maior controle das relações entre os indivíduos, exigência indispensável para o funcionamento de suas enormes estruturas e a manutenção do individualismo básico que as forma (Dumont, 1991; Elias, 1994). A administração e controle das relações interpessoais é tarefa da lei, pois dela depende o funcionamento das instituições. Não há mais lugar para soluções pessoais ou familiares para os conflitos.

Seguindo este raciocínio, podemos notar uma certa tendência a se associar os conceitos de internalidade e de individualismo, mas o exemplo japonês mostra que isto nem sempre é adequado: Kimura (1993), comparando pacientes deprimidos alemães e japoneses, sutilmente observou que a culpa entre os japoneses se dá com muito mais intensidade em relação aos outros, enquanto os sentimentos culposos dos alemães se ligavam a erros pessoais. À diferença do individualismo ocidental, o chamado "ego partilhado” das culturas orientais seria, segundo o autor, responsável por essas diferenças. Separamos então a vergonha da culpa e, desta forma, podemos fazer a interessante constatação de que a internalidade pode se desenvolver por caminhos diferentes do individualismo ocidental.

A externalidade parece ter uma estreita relação com a concepção cíclica da temporalidade, que é determinada pelos eventos da natureza, independente da vontade humana. O tempo contínuo só pode existir de forma internalizada, condicionando em sua estrutura seqüencial todas as atividades do sujeito. 


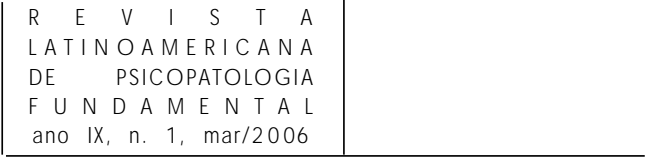

\section{A fenomenologia das vivências do tempo e da atribuição de causalidade (responsabilidade) como determinantes psicopatológicos}

A estreita relação do sentimento de responsabilidade com o estresse psicossomático já foi abundantemente demonstrada em inúmeros estudos clínicos e experimentais. Estudos feitos com primatas na década de 1960 já evidenciavam amplamente que a responsabilidade em evitar choques elétricos provocava úlceras nos animais, enquanto nos macacos que levavam os choques, mas não podiam evitá-los, nada acontecia.

É importante ressaltarmos, no entanto, que a correlação psicopatológica não pode ser feita de maneira superficial. Se o relógio do Coelho Branco de Alice provoca ansiedade e tensão, o tédio e a rotina também provocam aborrecimento e irritação. O personagem de Chaplin em Tempos modernos enlouquece de tanto apertar parafusos. Na literatura popular, vende-se a idéia simplória de que a vida campestre, ou a vida na selva seriam menos estressantes ou mais saudáveis que a vida nas cidades. Isso não passa de uma ingênua persistência do mito do bom selvagem de Rousseau. Na realidade, tanto os sentimentos de previsibilidade, repetição e segurança das concepções cíclicas do tempo quanto os sentimentos de indeterminação, criatividade e liberdade das concepções contínuas podem ser provocadores de estresse, caso sejam egodistônicos, ou estejam em desacordo com a estrutura da personalidade.

O grande problema é a proporção entre a gratificação proporcionada pelo ambiente sociocultural e a angústia provocada por suas exigências ou por suas omissões. Assim, autonomia e segurança mostram-se inversamente proporcionais. Vemos na patologia social e do trabalho que o grande problema é quando o sentimento de segurança não acompanha mais a falta de autonomia, ou quando a liberdade não se soma à incerteza criando um binômio insuportável: dúvida e opressão (desequilíbrio na balança liberdade/segurança).

\section{Patoplastia e patogênese}

Patoplastia, por oposição a patogênese, é uma expressão introduzida em 1923 por Birnbaum e que tem sido usada na etnopsiquiatria no sentido de dar à cultura um papel moldador dos quadros psiquiátricos, mas não essencialmente causal. Este conceito foi combatido pelos antropólogos radicais que não admitiam qualquer realidade intrínseca à doença psiquiátrica, fora da cultura.

À parte os sectarismos, porém, a clínica demonstra que há uma hierarquia de sintomas que vão desde os mais profundos, menos patoplásticos e menos 
suscetíveis de variação cultural, aos mais superficiais, essencialmente patoplásticos. Isto não significa que qualquer sintoma, profundo ou não, deixe de sofrer alguma influência cultural. O grande problema para o diagnóstico psicopatológico é que os sintomas secundários - ou superficiais - costumam ser os mais aparentes, os que chamam mais a atenção, especialmente por envolverem a quebra das normas e expectativas sociais. É aqui que surgem as culture-bound syndromes e se origina a maior parte dos erros diagnósticos. E é também exatamente neste ponto que se encontra a maior fraqueza prática dos critérios “objetivos” de diagnósticos, como os DSMs e CIDs. A busca da objetividade ontológica (e não apenas epistemológica) conduz à concretude cientificista, valorizando apenas o que seja redutível ao estritamente biológico. Como observam Russo e Henning (1999): “... o pressuposto empiricista implicado nessa posição 'ateórica' implicou, de fato, a adoção de uma visão fisicalista da perturbação mental.” Assim esse “ateoricismo” não apenas é mais uma visão teórica, mas uma visão teórica especialmente estreita e empobrecedora (Kleinman, 1985 e 1988).

\section{Diagnóstico diferencial}

As diferenças nas concepções temporais podem confundir as avaliações psicopatológicas menos cuidadosas. Sem uma compreensão fenomenológica ou etnopsiquiátrica mais profunda, o fatalismo, a resignação e o extremo conformismo, comuns em certas populações, podem ser interpretados como indiferença e diagnosticados como embotamento afetivo, dentro do pacote de "sintomas negativos” da esquizofrenia. Em outro texto (Bastos, 1997), dei como exemplo o caso de um paciente de manicômio judiciário, um sertanejo, que cometera um homicídio, mas não apresentava nenhum quadro psiquiátrico. Seu laudo pericial, no entanto, apontava para uma suposta esquizofrenia, baseando-se exatamente nesses "sintomas negativos". A metáfora "Vidas Secas", título célebre de Graciliano Ramos, ilustra com rara felicidade essa diferença cultural.

Affonso Romano de Sant'Anna, em uma crônica de jornal, menciona o caso, documentado em uma reportagem, de uma menina de área rural do interior que bebia sua água tranqüilamente numa lata usada de agrotóxico, expressando a sua perplexidade com a nossa displicência, o nosso descaso pela vida. No entanto, essa inconseqüência talvez não se encontre realmente neste tipo de pessoa, muito semelhante àquelas que provocaram o acidente radioativo em Goiânia. Talvez a inconseqüência esteja muito mais naqueles que impõem práticas que exigem projetos complexos, planejamento seqüencial e execução rigidamente disciplinada para populações que vivem sob um outro tempo, um tempo soberano, natural, que subjuga o destino. 


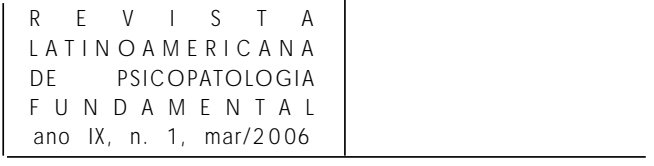

Kimura (1992, 1993) refere-se aos aspectos antecipativos do delírio esquizofrênico, em contraste com os sentimentos fatalistas dos estados melancólicos e delírios crônicos. Em ambas as situações ocorre uma redução temporal em relação ao futuro ou ao passado, respectivamente. Minkowski (1995) destacou a importância da vivência do tempo na psicopatologia da esquizofrenia. Segundo ele, a esquizofrenia consiste fundamentalmente numa perda do elã vital, o que impede o esquizofrênico de manter um contato com a realidade que não seja circunstancial ou superficial. O tempo parece inexistir, e assim, nem o trabalho nem o descanso, nem o sofrimento nem o prazer, parecem adquirir qualquer sentido. Às vezes parece só ser possível alguma mudança pela transformação ou por um processo de morte e ressurreição. Fora destes episódios, a chamada indiferença afetiva então se torna predominante. Assim, mesmo evoluindo por surtos, há um elemento de cronicidade intrínseco ao quadro (Lantéri-Laura, 1997).

Isto aparenta ser muito pouco compatível com as necessidades prementes de estreito controle e programação do tempo nas sociedades modernas. Talvez por isso alguns autores (como Devereux, 1970) chegassem até a considerar a esquizofrenia como uma doença da sociedade moderna. De acordo com um conhecido estudo multicêntrico da OMS (Jablensky, Sartorius et al., 1992) parece haver um melhor prognóstico para a esquizofrenia no chamado Terceiro Mundo, apesar da escassez de recursos. Um dos fatores que talvez condicionasse esses resultados seria uma maior tolerância dos povos de culturas tradicionais para com a esquizofrenia. Neste caso, as concepções não-seqüenciais da temporalidade poderiam representar um importante papel.

Num quadro reativo de depressão, a quebra das seqüências temporais é extremamente mobilizadora para as sociedades que exigem atividade laborativa regular e planejada. Numa sociedade tradicional, porém, um período de inatividade pode ser bem tolerado, até que a personalidade encontre forças para se recuperar. Não é por outra razão que a atual “epidemia” de depressão tem seu epicentro nos Estados Unidos, onde as distinções psicopatológicas jasperianas entre reação, processo e desenvolvimento nunca chegaram a se estabelecer.

\section{A psiquiatria como prática científica e como produção cultural}

\section{Modernidade, individualismo e representações culturais}

Faz parte dos pressupostos ideológicos do individualismo da moderna sociedade pós-industrial a globalização e a homogeneização das culturas, pois se vê como a única forma viável de existência (que já chegou ao “fim da história”). 
“Cultura” passa a ser um sinônimo de folclore, à qual só restam duas alternativas: transformar-se em atração turística ou desaparecer. No entanto, dentro dos próprios centros de produção ideológica dessa cultura globalizada surgem milhares de núcleos de resistência a essas mudanças. No mundo, os nacionalismos se exacerbam. Nos Estados Unidos, cultos, seitas, e mesmo religiões, são fundadas diariamente, e o seu mercado parece inesgotável. Isto nos faz pensar que se duzentos anos de individualismo em nada mudaram as necessidades humanas, o culto à medicina, ao corpo, à saúde, às dietas, às vitaminas e aos medicamentos tornou-se tão ou mais intenso que o de qualquer outra divindade “cultural”.

\section{A relação entre o psiquiatra e o curandeiro}

O médico é o intermediário entre o doente e a divindade, entre a vida e a morte; toda a angústia das incertezas humanas vem às suas mãos. Partimos do princípio de que todo e qualquer terapeuta, seja ele médico ou feiticeiro, tem como função social o acolhimento e a resolução de duas necessidades fundamentais: o alívio do sofrimento do doente (dor, incapacidade, frustração, angústia etc.) e o alívio do sofrimento da sociedade face à doença (ameaça, fragilidade, incerteza, insegurança, descrença etc.).

Assim, cabe a ele impedir que os laços entre o doente e o grupo se fragilizem pelo isolamento, pela desesperança ou pelo abandono. Em sociedades mais complexamente organizadas e individualizantes, o atendimento à primeira necessidade automaticamente reflete na segunda; ambas, porém, devem ser atendidas. Não é difícil compreender que a psiquiatria, por sua própria natureza, está ainda mais envolvida com o atendimento às necessidades específicas da sociedade do que qualquer outra especialidade médica. Seja aonde for localizada a fonte do sofrimento (externa ou interna), o trabalho é o mesmo: cumprir os rituais necessários e fornecer os tratamentos. Isto nada tem a ver com o charlatanismo, que é uma forma de exploração do desamparo e da fragilidade humana. Aliás, podemos imaginar que até mesmo o mais descarado charlatanismo pode ocasionalmente ser útil, se não impedir o doente de obter algum outro tratamento mais eficaz e realmente aliviar-lhe a dor.

Psicodinâmica e cultura

Procuramos demonstrar os elementos psicodinâmicos presentes nas diversas culturas, e estudar as maneiras como são utilizados na interpretação, como uma mitologia (no sentido usado por Lévi-Strauss, 1976, 1977) à qual a pessoa com problemas pode ser reintegrada. Cada elemento mitológico tem um papel explanatório e organizador da vida social; papel que se torna reparador e 


\begin{tabular}{lccccc|l}
$R \quad E$ & $V$ & $I$ & $S$ & $T$ & $A$ \\
LATIN O A M E RIC A N A & \\
$D E$ & PSICO PATO LO GIA & \\
$F$ U N D A M & E N T A L & \\
ano IX, & n. & 1, & mar/2006 & \\
\hline
\end{tabular}

terapêutico quando aplicado nas situações patológicas. Queremos ressaltar que pode perfeitamente existir grande profundidade psicodinâmica em formas de psicoterapia que não obedecem às regras individualizantes da internalidade e da seqüencialidade temporal.

$\mathrm{Na}$ Bahia, os estados dissociativos podem ser vistos como elementos terapêuticos, em que cada entidade sobrenatural pode exercer o seu papel específico de cura ou reintegração social. Já nos Estados Unidos, os quadros dissociativos são vistos como uma patologia em si mesma, anteriormente descrita como "esquizofrenia" - na forma exageradamente abrangente dos americanos e mais tarde diagnosticada como "personalidade múltipla”, uma típica culturebound syndrome não encontrada em nenhum outro lugar. Desta forma, se num lugar o quadro é visto como uma forma terapêutica, que produz algo estável, uma maneira de ser, no outro é considerado algo patológico em si mesmo, de natureza disruptiva e que exige tratamento.

\section{As vivências temporais e a psicoterapia}

Vemos que as sociedades ocidentais - individualistas - tendem à internalização da responsabilidade social, da doença e da cura, sejam estas biológicas ou psicológicas. O tratamento deve então ser contínuo, progressivo, com início, meio e fim marcados. Nas sociedades tribais, o tratamento costuma ser descontínuo, repetitivo, cíclico, em periódicas renovações. Apesar de ambas as perspectivas incluírem diagnósticos, estratégias e técnicas, o seu curso se dá de forma muito diferente.

Quando um estagiário de psiquiatria ou psicologia, atendendo um paciente em ambulatório, marca sessões semanais de psicoterapia e o paciente não comparece, o seu supervisor certamente tende a dizer que o "problema" se deve à fragilidade do vínculo terapêutico e/ou à resistência inconsciente. A mesma explicação pode ser usada quando o paciente retorna, some de novo e depois retorna novamente. Em nenhum momento se pensa em questionar a adequação do método terapêutico. Lembro-me que há uns quinze anos, um colega ${ }^{4}$ relatoume que os seus pacientes de ambulatório que mantinham o melhor vínculo terapêutico eram justamente os que só vinham a cada quinze dias ou a cada mês. Desde então, jamais vi qualquer estudo, observação ou sequer uma menção a esse assunto.

Na nossa prática psiquiátrica, nem as tendências culturais à externalidade, nem o relacionamento destas com os conceitos cíclicos do tempo são levadas em

4. Dr. Ricardo Maciel da Costa, psiquiatra da Universidade Federal Fluminense. 
conta, seja no diagnóstico, seja na terapêutica (Bastos, 1996). Como destaca Tobie Nathan (1995): “... dans les societés non occidentales, les médicaments ne sont efficaces que dans la mesure où ils instaurent puis aident à maintenir la théorie générale selon laquelle il faut â tout prix - et it l'aide de tous les dispositifs disponibles - disjoindre symptôme et personne”.

Os mesmos aspectos psicodinâmicos que a psicoterapia tenta reconstruir progressivamente podem ser percebidos e redirecionados num tratamento religioso, dependendo da habilidade pessoal do xamã ou feiticeiro. Ocorre sempre uma mais ou menos bem-sucedida reinterpretação dos problemas emocionais do paciente de acordo com perspectiva mitológica do analista ou do feiticeiro. As principais diferenças tendem a ocorrer nos aspectos temporais e de atribuição de responsabilidade, pois a feitiçaria tende a criar um espaço terapêutico ritualizado e periódico para as manifestações patológicas, sem qualquer preocupação de progressão ou continuidade, já que o problema é visto como inteiramente externo ao paciente. O mais difícil neste caso é compreender que não existe uma idéia de progresso ou evolução do indivíduo para a cura, mas sim uma espécie de reequilíbrio de forças externas em sua relação com o paciente.

\section{Referências}

Augras, M. O duplo e a metamorfose. Petrópolis: Vozes, 1983. 1995.

Alteridade e dominação no Brasil - Psicologia e cultura. Rio de Janeiro: Nau,

Aveni, A. Empires of Time: Calendars, Clocks and Cultures. New York: Kodansha, 1995.

Bastide, R. As religiões africanas no Brasil. 2 vol. São Paulo: Pioneira/Edusp, 1971.

Bastos, C. L. Delírio persecutório e depressão: uma abordagem transcultural e seus aspectos terapêuticos. Jornal Brasileiro de Psiquiatria, v. 44, n. 10, p. 507-13, 1995.

O tempo, as representações sociais de doença e a psicoterapia. Informação Psiquiátrica, v. 15, n. 4, p. 139-44, 1996.

Tempo, idade e cultura: uma contribuição à psicopatologia da depressão no idoso. Segunda Parte: uma investigação sobre a temporalidade e a medicina. Revista Latinoamericana de Psicopatologia Fundamental, São Paulo, ano VIII, n. 4, p. 738-53, 2005.

Campbell, J. K. Honor, Family and Patronage. Londres: Oxford University Press, 1974.

DaMatTA, R. Carnavais, malandros e heróis. 5. ed. Rio de Janeiro: Guanabara Koogan, 1990. 


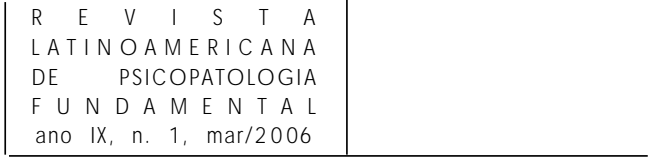

Devereux, G. Essais d'Ethnopsychiatrie Génèrale. Paris: Gallimard, 1970.

DuARTE, L. F. Da vida nervosa nas classes trabalhadoras urbanas. Rio de Janeiro: Jorge Zahar, 1986.

In: Figueira, S. (org.). Cultura e psicanálise. São Paulo: Brasiliense, 1985.

Dumont, L. Essais sur l'individualisme. Paris: Seuil, 1991.

Eliade, M. Le Mythe de L'Éternel Retour. Paris: Gallimard, 1949.

Tratado de história das religiões. São Paulo: Martins Fontes, 1993.

Elias, N. A sociedade dos indivíduos. Rio de Janeiro: Zahar, 1994.

Evans-Pritchard, E. E. Os Nuer. São Paulo: Perspectiva, 1978.

Fabian, J. Time and the Other. New York: Columbia University Press, 1983.

Fadiman, A. The Spirit Catches You and You Fall Down. New York: Farrar, Straus \& Giroux, 1997.

Gould, S. J. Seta do tempo, ciclo do tempo. São Paulo: Companhia das Letras, 1991.

O milênio em questão. São Paulo: Companhia das Letras, 1999.

Hess, D. J. Science and Technology in a Multicultural World. New York: Columbia University Press, 1995.

Jablensky, A.; Sartorius, N.; ERnBerg, G. et al. Schizophrenia: manifestations, incidence and course in different cultures. A WHO ten-country study. In: Psychological Medicine monograph supplement, 20, 1992.

JASPers, K. Psicopatologia geral. Rio de Janeiro: Atheneu, 1973, 2 vols.

Kimura, B. Écrits de Psychopathologie Phénoménologique (orig. em japonês). Paris: PUF, 1992.

Aida (Interpersonal) Psychopathology. In: Ріснот, P. \& Rein, W. The Clinical Approach in Psychiatry. Le Plessis-Robinson, Synthélabo, 1993. (Les Empêcheurs de Penser en Rond)

KLeinman, A. Rethinking Psychiatry. New York: MacMillan, 1988.

Kleinman, A. \& Good, B. (orgs.) Culture and Depression. Berkeley: University of California Press, 1985.

Landes, D. S. Revolution in Time: Clocks and the Making of Modern World. Cambridge: Harvard University Press, 1983.

Lantéri-Laura, G. La Chronicité en Psychiatrie. Le Plessis-Robinson, Synthélabo, 1997. (Les Empêcheurs de Penser en Rond)

Laplantine, F. Antropologia da doença. São Paulo: Martins Fontes, 1991.

LeAch, E. R. Repensando a antropologia. São Paulo: Perspectiva, 1974. 
Le Goff, J. Para um novo conceito de Idade Média. Lisboa: Estampa, 1980.

LÉvi-Strauss, C. Structural Anthropology. New York: Basic Books, 1976. v. II. Structural Anthropology. Londres: Peregrine Books, 1977.

Levine, R. A Geography of Time. New York: Basic Books, 1997.

Matricon, J. \& Roumette, J. L'Invention du Temps. Paris: Presses Pocket, 1991.

Meneut, M. (org.). Penser le temps. Paris: Ellipses, 1996.

Minkowski, E. Le temps vécu. Paris: PUF, 1995.

Traité de Psychopathologie. Le Plessis-Robinson, Synthélabo, 1999. (Les Empêcheurs de Penser en Rond).

Natal, S.; Valente, J.; Gerhardt, G.; Penna, M. L. Situação bacteriológica dos doentes de tuberculose que abandonaram o tratamento. Boletim de Pneumologia Sanitária, v. 7, n. 2, p. 30-7, 1999.

Nathan, T. Manifeste pour une Psychopathologie Scientifique. In: Stengers, I. \& Nathan, T. Médecins et Sorciers. Le Plessis-Robinson, Synthélabo, 1995. (Les Empêcheurs de Penser en Rond).

NeEdham, J. La Gran Titulación: Ciencia y Sociedad en Oriente y Occidente. Madrid: Alianza, 1971.

Queiroz, M. S. Estratégias de consumo em saúde entre famílias trabalhadoras. Cadernos de Saúde Pública. Rio de Janeiro, v. 9. n. 2, p. 272-82, 1993.

Rabelo, M. C. Religião e cura. Cadernos de Saúde Pública. Rio de Janeiro, v. 9, n. 2, p. 316-25, 1993.

Rotter, J. B. Generalized expectancies for internal versus external control of reinforcement. Psychological Monographs, v. 33, n. 1, p. 300-3, 1966.

Russo, J. \& Henning, M. F. O sujeito da “psiquiatria biológica” e a concepção moderna de pessoa. Antropolítica, n. 6, p. 39-55, 1999.

Sevalho, G. Uma abordagem histórica das representações sociais de saúde e doença. Cadernos de Saúde Pública, Rio de Janeiro, v. 9, n. 2, p. 349-63, 1993.

Simon, B. Mind and Madness in Ancient Greece. Ithaca: Cornell, 1978.

Sougey, E. B. Aspectos transculturais das depressões. Jornal Brasileiro de Psiquiatria, v. 41, n. 4, p. 185-9, 1992.

Sow, I. Psychiatrie dynamique africaine. Paris: Payot, 1977.

Les Structures Anthropologiques de la Folie en Afrique Noire. Paris: Payot, 1978.

Stainbrook, E. A Cross-Cultural Evaluation of Depressive Reactions. In: Ноch, P. H., \& Zubin, J. (org.). Depression. New York: Grune \& Stratton, 1954. 


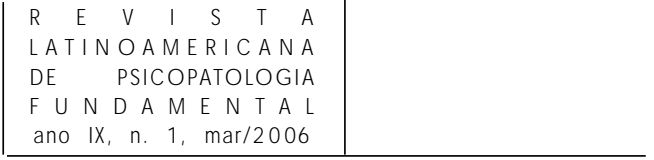

SutTer. L'Anticipation. Paris: PUF, 1983.

Szamosi, G. Tempo e espaço. Rio de Janeiro: Jorge Zahar, 1994.

Toynbee, A. O ciclo do tempo. In: O tesouro da Enciclopédia Britânica. 2. ed. Rio de Janeiro: Nova Fronteira, 1994.

Ulansey, D. The Mithraic Mysteries: Cosmology and Salvation in the Ancient World. Oxford: Oxford University Press, 1989.

Vogel, A.; Mello, M. A. S.; Barros, J. F. P. Galinha d'angola. Iniciação e identidade na cultura afro-brasileira. 2. ed. Rio de Janeiro: Pallas, 1998.

Weber, M. A ética protestante e o espírito do capitalismo. São Paulo: Pioneira, 1994.

Weissman, M. M.; Myers, J. K. Affective disorders in a US urban community: the use of research diagnostic criteria in an epidemiological survey. Archives of General Psychiatry, n. 35, p. 1304-11, 1978.

Wertheim, M. The Pearly Gates of Cyberspace. New York: W.W. Norton, 1999.

Whitrow, G. J. O tempo na história. Rio de Janeiro: Zahar, 1993.

Zerubavel, E. Hydden Rhytms: Schedules and Calendars in Social Life. Berkeley: University of California Press, 1981.

\section{Resumos}

Buscamos aquí relacionar dos aspectos fundamentales de las intuiciones culturales sobre el pasage del tiempo - la temporalidad cíclica y continua - con la terapéutica médica y más especialmente con la psicopatología, en una visión crítica del constructo moderno de la depresión en la vejez. Inspirado en perspectivas antropológicas, el texto busca apoyo en la experiencia clínica diaria y en la actitud fenomenológica que la orienta. En las concepciones culturales del tiempo que tienden a percibir su pasage de forma predominantemente cíclica, envejecer es parte de un movimiento eterno. La familia se perpetúa en sus descendientes, en sus tradiciones, en el vinculo con la tierra o en el ejercicio del oficio familiar. Las transformaciones culturales que han proporcionado el pasage para enfoques más direccionales del tiempo van destacando cada vez más el rol individual en la historia social. Cuanto más dificultoso sea el pasage de Weltanschauungen tradicionales - de tendencia circular, fatalista, repetitiva y eterna - para otras, de tendencia individualizante, burocratizante, planeadora y sucesiva, mayores serán las dificultades para una senectud satisfactoria, y mayor la tendencia a la medicalización de ese fracaso. Esta es la segunda parte de una serie de tres artículos.

Palabras claves: Psicopatología y cultura, temporalidad y medicina, depresión en el anciano, psicogeriatría 
Nous cherchons ici à relationer deux aspects fondamentales des conceptions intuitives culturelles sur la passage du temps - la temporalité cyclique e la continue - avec la thérapeutique médicale et plus spécialement avec la psychopathologie, dans une vision critique de la conception moderne de la dépression chez la vieillesse. Inspirée des perspectives anthropologiques, le texte se soutien dans l'expérience clinique de chaque jour et dans l'attitude phénoménologique guidant cette pratique. Dans las conceptions culturelles du temps de tendance cyclique, le vieillissement est part d'un mouvement éternel et la famille se perpétue par ses descendants, sas traditions, ses liens avec la terre ou l'exercice du métier familier. Les transformations culturelles que proportionnent la passage pour un approche plus directionnel du temps détachent de plus em plus le rôle individuel das l'histoire social. La plus difficile est la passage des perspectives traditionnelles, tendants à la circularité, à la répétition, au fatalisme et à l'éternité, pour autres de tendance à l'individualisation, à la bureaucratie, à la planification et à la succession, les plus grandes les entraves à une vieillesse satisfaisante et la tendance à la médicalisation de ce problème. Cet article est la seconde part d'une série de trois.

Mots clés: Psychopatologie et culture, temporalité et médicine, depression et l'âgée, psychogeriatrie

Two fundamental aspects of intuitive cultural conceptions of the passage of time - cyclical and continuous - are related here to medical therapy and psychopathology, in a critical view of depression in old age as a modern construct. Although inspired by anthropological perspectives, this article is based on daily clinical experience which uses a phenomenological approach. In predominantly cyclical cultural perceptions of time the process of ageing is part of an eternal movement. Families perpetuate themselves in their descendants, their traditions, ties with the land or the practice of family crafts or skills. Cultural transformations that give rise to more directional approaches to the passage of time tend to increasingly implement individual roles in social history. The more difficult it is to effect a passage from a fatalist, repetitive, cyclical, eternal and traditional Weltanschauungen to individualizing, bureaucratizing, planning and successive Weltanschauungen, the greater the probability of unsuccessful old age and the consequent medicalization of this failure. This paper is the second part of a three-part series.

Key words: Psychopathology and culture, temporality and medicine, depression and ageing, psychogeriatrics 